\title{
А.О. Зінченко
}

Національний університет оборони України, Київ

\section{МАТРИЧНА ФОРМАЛІЗАЦІЯ ВІДГУКУ БАГАТОПОЗИЦІЙНОЇ ІНТЕГРОВАНОЇ СИСТЕМИ ЗВ'ЯЗКУ ТА РАДІОЛОКАЦІЇ У РЕЖИМІ ЗВ'ЯЗКУ}

В статті приведено варіант моделі функиіонування інтегрованої багатопозиційної системи зв'язку та радіолокації за принципом МІМО у випадку застосування в приймальних позиціях плоских цุифрових антенних решіток. Запропонована модель формалізує відгук приймального сегмента системи за умови випромінювання одним або декількома передавачами кореспондентів багаточастотних сигналів на різних довжинах електромагнітних хвиль.

Ключові слова: мобільна станція зв'язку, інтегрована багатопозиційна система зв'язку та радіолокації, циифрова антенна решітка, матрична модель відгуку.

\section{Вступ}

Активний розвиток обчислювальної техніки призвів до бурхливого розвитку нових технологій створення систем зв'язку i радіолокації, що спираються на застосування принципу МIMO. Спираючись на ідентичність технічних рішень при створенні цифрових антенних решіток для виконання завдань зв'язку та радіолокації, можна створити інтегровану багатопозиційну систему зв'язку та радіолокаційної розвідки ІСЗРЛ. Основним варіантом функціонування приймальнопередавальних ЦАР при цьому слід обрати режим мультикористувальницького МIMO (мультиMIMO). Найпростішим варіантом функціонування ІСЗРЛ є виконання завдань зв'язку і радіолокації з розділом у часі. Розробка теоретичних основ функціонування таких систем була започаткована в роботах [1-3]. В [1, 4, 5] була проведена формалізація відгуків приймально-передавальних ЦАР багатопозиційної ІСЗРЛ для спрощених випадків випромінювання кореспондентами одночастотних сигналів для режиму зв'язок та опромінювання кількох цілей одночастотними зондуючими сигналами. Опис відгуків сигнальної суміші на приймальній ЦАР спирається на застосування в аналітичній моделі блокового матричного добутку Хатри-Рао, блокового добутку Кронекера та блокового транспонованого торцового добутку матриць [6, 7] .

Проте розглянуті моделі функціонування ІСЗРЛ були обмежені лише описом ситуації наявності односигнального або кількох односигнальних кореспондентів. Вважається за доцільне удосконалити запропоновану модель за рахунок застосування багаточастотних сигналів кількома кореспондентами для режиму функціонування ІСЗРЛ - “зв'язок”.

\section{Мета статті}

Формування матричних моделей відгуків цифрових антенних решіток на багаточастотні сигнали деякої кількості кореспондентів, що надходять на приймальну підсистему ICЗРЛ.

\section{Виклад основного матеріалу дослідження}

При формалізації відгуків напруг сигналів на виходах приймальних каналів багатопозиційної ICЗРЛ будемо спиратись на традиційну форму їx представлення у матричному вигляді $[8,9]$ :

$$
U=P \cdot A+n,
$$

де $\mathrm{U}$ - блоковий вектор комплексних напруг сигналів після виходів частотних фільтрів просторових каналів сукупності ЦАР багатопозиційної МСЗРЛ;

$\mathrm{P}$ - сигнальна матриця;

А - блоковий вектор комплексних амплітуд сигналів;

$\mathrm{n}$ - блоковий вектор напруг шумів.

При такому описі формалізація відгуків приймальних ЦАР зводиться до визначення структури матриці Р. В [4] був детально розглянутий режим радіолокації у випадку застосування одночастотних зондувальних сигналів. У цьому випадку від кожного об'єкта радіолокаційної розвідки перевідбивався багаточастотний сигнал. Структура сигнальної матриці при застосуванні блокового добутку Кронекера має вигляд:

а) для лінійних антенних решіток 


$$
P=Q[\otimes] F,
$$

б) для плоских антенних решіток

$$
P=(Q[\otimes] V)[\otimes] F,
$$

де $[\otimes]$ - символ блокового добутку Кронекера;

$$
F=\left[\begin{array}{ccc:c:ccc}
F_{11}\left(\omega_{11}\right) & \cdots & F_{11}\left(\omega_{1 E}\right) & \cdots & F_{11}\left(\omega_{M 1}\right) & \cdots & F_{11}\left(\omega_{M E}\right) \\
\vdots & \ddots & \vdots & \vdots & \vdots & \ddots & \vdots \\
F_{S 1}\left(\omega_{11}\right) & \cdots & F_{S 1}\left(\omega_{1 E}\right) & \cdots & F_{S 1}\left(\omega_{M 1}\right) & \cdots & F_{S 1}\left(\omega_{M E}\right) \\
\hdashline F_{1 T}\left(\omega_{11}\right) & \cdots & F_{1 T}\left(\omega_{1 E}\right) & \cdots & F_{1 T}\left(\omega_{M 1}\right) & \cdots & F_{1 T}\left(\omega_{M E}\right) \\
\vdots & \ddots & \vdots & \vdots & \vdots & \ddots & \vdots \\
F_{S T}\left(\omega_{11}\right) & \cdots & F_{S T}\left(\omega_{1 E}\right) & \cdots & F_{S T}\left(\omega_{M 1}\right) & \cdots & F_{S T}\left(\omega_{M E}\right)
\end{array}\right]
$$

$\mathrm{F}$ - блокова матриця AЧX $\mathrm{S}$ частотних фільтрів, синтезованих за допомогою дискретного перетворення Фур'є на Е частотах відбитих від М цілей Е сигналів;

$$
Q=\left[\begin{array}{c:c:c}
Q_{11}\left(x_{1}\right) & \ldots & Q_{11}\left(x_{M}\right) \\
\vdots & \ddots & \vdots \\
Q_{R 1}\left(x_{1}\right) & \ldots & Q_{R 1}\left(x_{M}\right) \\
\hdashline Q_{1 T}\left(x_{1}\right) & \cdots & Q_{1 T}\left(x_{M}\right) \\
\vdots & \ddots & \vdots \\
Q_{R T}\left(x_{1}\right) & \ldots & Q_{R T}\left(x_{M}\right)
\end{array}\right] \text { - блокова }
$$

матриця діаграм спрямованості антенних елементів в азимутальній площині $Q_{r t}\left(x_{m}\right)$ у напрямках на m-е джерело сигналів з кутовою координатою $\left(x_{m}\right)$;

$$
V=\left[\begin{array}{c:c:c}
V_{11}\left(y_{1}\right) & \cdots & V_{11}\left(y_{M}\right) \\
\vdots & \ddots & \vdots \\
V_{D 1}\left(y_{1}\right) & \cdots & V_{D 1}\left(y_{M}\right) \\
\hdashline V_{1 T}\left(y_{1}\right) & \cdots & V_{1 T}\left(y_{M}\right) \\
\vdots & \ddots & \vdots \\
V_{D T}\left(y_{1}\right) & \cdots & V_{D T}\left(y_{M}\right)
\end{array}\right] \text { - блокова }
$$

матриця діаграм спрямованості антенних елементів в кутомісцевій $V_{d t}\left(y_{m}\right)$ площині у напрямках на m-е джерело сигналів з кутовою координатою $\left(y_{m}\right)$;

$\mathrm{r}=1, \ldots, \mathrm{R}-$ порядковий номер антенного елемента в антенній решітці у відповідній кутовій площині;

$\mathrm{d}=1, \ldots, \mathrm{D}$ - порядковий номер антенного елемента у стовпці антенної решітки;

$\mathrm{t}=1, \ldots, \mathrm{T}$ - порядковий номер позиції ЦАР у багатопозиційній системі.

Якщо умовно замінити цілі, від яких перевідбиваються одночастотні сигнали, на джерела багаточастотних сигналів у режимі зв'язку, то аналогічні співвідношення слід взяти за основу і для формування матричної моделі відгуку приймальної ЦАР у режимі роботи на зв'язок, коли сценарій функціонування системи зв'язку зводиться до передачі Е-частотних пакетів сигналів 3 одноантенних терміналів М кореспондентів, на розосереджені по кількох позиціях приймальні ЦАР (рис. 1). 3 точки зору фізики процесів прийому сигналів на приймальних позиціях, зазначений сценарій буде спорідненим 3 ситуацією, що зводиться до застосування на М терміналах Еелементних передавальних (активних) антенних решіток, кожен 3 активних елементів яких випромінює одночастотний інформаційний сигнал в режимі МIMO (рис. 2).

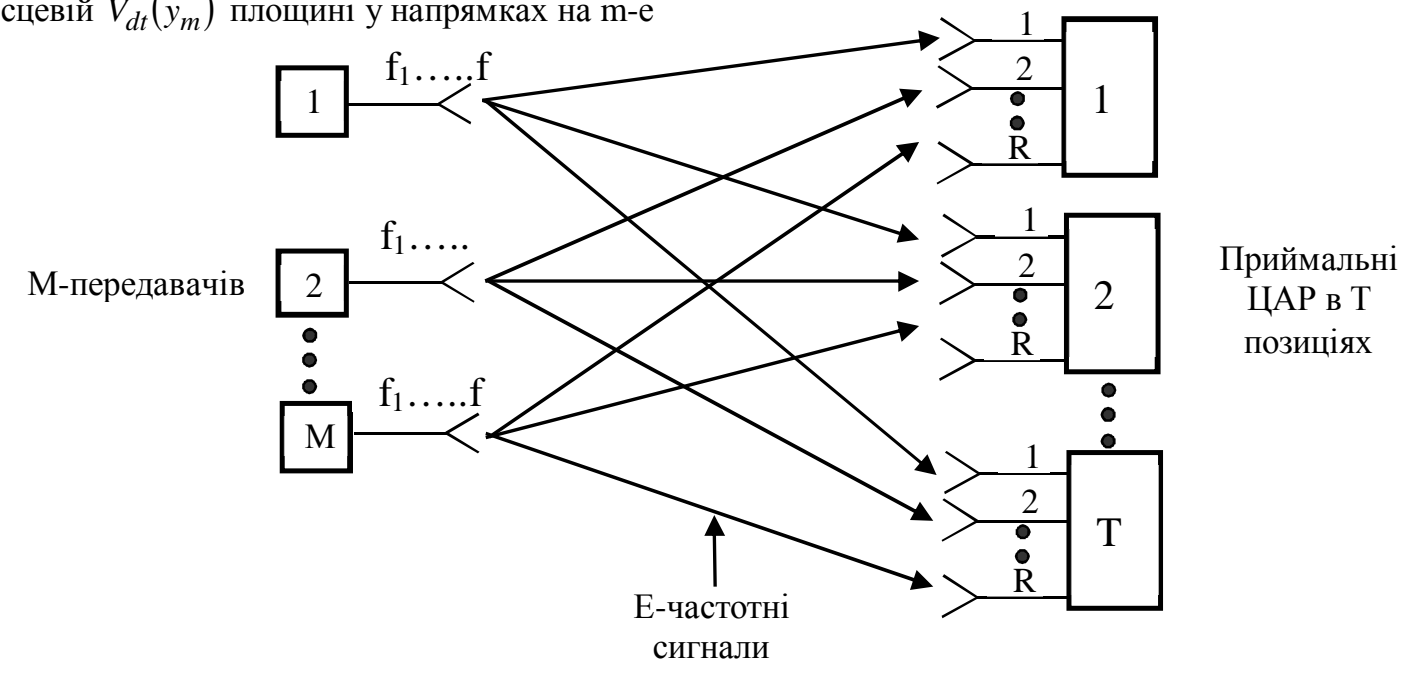

Рис. 1. Режим зв'язку з випромінюванням Е-частотних сигналів М передавачами 


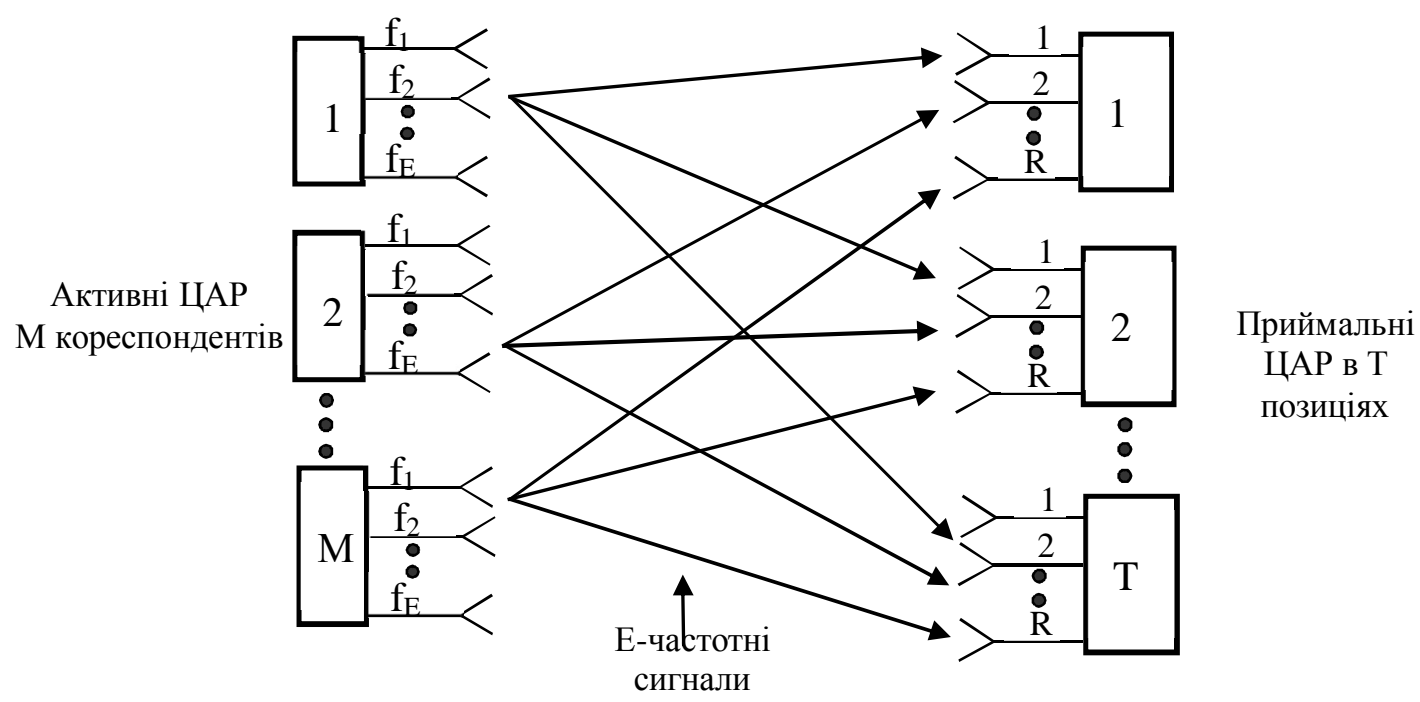

Рис. 2. Режим зв'язку з випромінюванням одночастотних сигналів Е-елементними активними антенними решітками, розташованими на М терміналах

Відмінність від розглянутого вище режиму радіолокації полягає у необхідності врахування матриць передаточних характеристик каналу МІМО в азимутальній і кутомісцевій площинах, а також формуванні матриці АЧХ частотних фільтрів $\mathrm{F}$ відповідно до типу сигналу, що застосовується. У разі використання сигналів OFDM вираз (3) модифікується до вигляду:

$$
P=\left(\left(Q \circ \tilde{H}_{Q}\right)[\otimes]\left(V \circ \tilde{H}_{V}\right)\right)[\otimes] F,
$$

де

$$
\tilde{H}_{Q}=\left[\begin{array}{c:c:c}
\tilde{h}_{Q 111} & \cdots & \tilde{h}_{Q 11 M} \\
\vdots & \ddots & \vdots \\
\tilde{h}_{Q R 11} & \cdots & \tilde{h}_{Q R 1 M} \\
\hdashline \tilde{h}_{Q 1 T 1} & \cdots & \tilde{h}_{Q 1 T M} \\
\vdots & \ddots & \vdots \\
\tilde{h}_{Q R T 1} & \cdots & \tilde{h}_{Q R T M}
\end{array}\right], \quad \tilde{H}_{V}=\left[\begin{array}{c:c:c}
\tilde{h}_{V 111} & \cdots & \tilde{h}_{V 11 M} \\
\vdots & \ddots & \vdots \\
\tilde{h}_{V D 11} & \cdots & \tilde{h}_{V D 1 M} \\
\hdashline \tilde{h}_{V 1 T 1} & \cdots & \tilde{h}_{V 1 T M} \\
\vdots & \ddots & \vdots \\
\tilde{h}_{V D T 1} & \cdots & \tilde{h}_{V D T M}
\end{array}\right]
$$

блокові матриці передавальних характеристик каналу MIMO в азимутальній $\tilde{h}_{Q r t m}$ і кутомісцевій $\tilde{h}_{V r t m}$ площинах у напрямках на m-е джерело сигналів 3 кутовими координатами $\left(x_{m}, y_{m}\right)$,

$\mathrm{r}=1, \ldots, \mathrm{R}-$ порядковий номер антенного

$$
Q=\left[\begin{array}{c:c:c}
Q_{11}\left(x_{1}\right) & \cdots & Q_{11}\left(x_{M}\right) \\
\vdots & \ddots & \vdots \\
Q_{R_{1}}\left(x_{1}\right) & \cdots & Q_{R_{1} 1}\left(x_{M}\right) \\
\hdashline Q_{I T}\left(x_{l}\right) & \cdots & Q_{1 T}\left(x_{M}\right) \\
\vdots & \ddots & \vdots \\
Q_{R_{T} T}\left(x_{l}\right) & \cdots & Q_{R_{T} T}\left(x_{M}\right)
\end{array}\right],
$$

де $\mathrm{R}_{\mathrm{t}}$ - максимальна кількість антенних елементів у рядку антенної решітки в t-й позиції МСЗРЛ; елементу в рядку антенної решітки; $\mathrm{d}=1, \ldots, \mathrm{D}-$ порядковий номер антенного елементу у стовпці антенної решітки;

$\mathrm{t}=1, \ldots, \mathrm{T}$ - порядковий номер позиції ЦАР.

Без розшарування матриць $Q, V, \tilde{H}_{Q}, \tilde{H}_{V}$ на блоки структура сигнальної матриці буде мати вигляд:

$$
P=\left(\left(Q \circ \tilde{H}_{Q}\right)[\mathbf{\square}]\left(V \circ \tilde{H}_{V}\right)\right)[\otimes] F .
$$

Відповідно, блоковий вектор комплексних амплітуд сигналів А, що має бути оцінений в режимі зв'язку, отримає таку структуру:

$$
A=\left[\begin{array}{lll:l:lll}
A_{11} & \cdots & A_{1 E} & \cdots & A_{M 1} & \cdots & A_{M E}
\end{array}\right]^{T} .
$$

При цьому виникає потреба в ідентифікації належності отриманих сигналів конкретній багатоантенній передавальній системі для збереження зв'язності отриманої інформації.

Подальше узагальнення виразів (4), (5) полягає в охопленні випадку, коли антенні системи у кожній позиції $\epsilon$ різними, тобто мають різну кількість елементів в ЦАР. Для цього достатньо в блокових матрицях Q та V при описі кількості елементів ввести додатковий індекс, що враховує номер позиції, зокрема:

$$
V=\left[\begin{array}{c:c:c}
V_{11}\left(y_{1}\right) & \cdots & V_{11}\left(y_{M}\right) \\
\vdots & \ddots & \vdots \\
V_{D_{1} 1}\left(y_{1}\right) & \cdots & V_{D_{1} 1}\left(y_{M}\right) \\
\hdashline V_{I T}\left(y_{1}\right) & \cdots & V_{1 T}\left(y_{M}\right) \\
\vdots & \ddots & \vdots \\
V_{D_{T} T}\left(y_{1}\right) & \cdots & V_{D_{T} T}\left(y_{M}\right)
\end{array}\right],
$$

$\mathrm{D}_{\mathrm{t}}$ - максимальна кількість антенних елементів у стовпці антенної решітки в $\mathrm{t}-и ̆$ позиції МСЗРЛ. 
Перевагою виразів (6) є можливість кооперативної обробки сигналів неоднотипних за форматом побудови приймальних ЦАР, від лінійних до плоских, в різних позиціях, що надає додаткові ступені свободи у формуванні багатопозиційної системи МСЗРЛ.

\section{Висновки}

Розроблено модель функціонування ІСЗРЛ в режимі зв'язок у випадку застосування в приймальних позиціях плоских ЦАР, а також випромінювання кількома передавачами багаточастотних сигналів на різних довжинах електромагнітних хвиль. Запропонована модель відгуку ЦАР ІСЗРЛ дозволить отримати нижню межу Крамера-Рао для дисперсій оцінок параметрів сигналів і здійснити аналіз ㄲi достовірності шляхом математичного моделювання процедур обробки сигналів в приймальному сегменті IC3РЛ.

Метою подальших досліджень є удосконалення запропонованої моделі та моделювання окремих аспектів функціонування i обробки сигналів вказаної ІСЗРЛ.

\section{Список літератури}

\author{
1. Зінченко А. О. Модель багатопозиційної \\ інтегрованої системи зв'язку $i$ радіолокачії на \\ основі мультикористувальницького методу МІМО / \\ А. О. Зінченко // Науково-виробничий збірник "Наукові \\ записки Украӥнського науково-дослідного інституту зв'язку”. - \\ 2014. - № 2(30). - C. 124-130. \\ 2. Слюсар В. І. Мультикористувальницький метод \\ МІМО в інтегрованій системі зв'язку та радіолокаиії $з$ \\ багатосекиійними ЦАР / В. І. Слюсар, А. О. Зінченко // \\ Матеріали науково-практичного семінару "Принципи \\ побудови інформаиійно-телекомунікаиійних вузлів \\ оперативної та стратегічної ланок управління Збройних \\ Сил Украӥни”, 2 грудня 2010 р. - К.: Національний \\ університет оборони Украӥни, 2010. - С. 80-82. \\ 3. Слюсар В. І. Технологія мульти -МІМО як засіб \\ апаратного поєднання систем з6'язку та радіолокації /
}

В. І. Слюсар, А. О. Зінченко // Доповіді та тези доповідей V науково-практичного семінару "Пріоритетні напрямки розвитку телекомунікаиійних систем та мереж спеціального призначення", 20, 21 жовтня 2010 р. - К.: Військовий інститут телекомунікації та інформатизації Національного технічного університету Украйни “Київський політехнічний інститут" - 2010. - C. 226, 227.

4. Зінченко А.О. Модель функиіонування багатопозиційної інтегрованої системи зв'язку і радіолокації у режсимі МІМО радіолокачії / А. О. Зінченко, В. І. Слюсар // Сучасні інформаційні технологіі у сфері безпеки та оборони. - 2014. - № 2(20). - С. 23 - 28.

5. Зінченко А.О. Модель функиіонування інтегрованої багатопозиційної системи зв'язку за принципом МІМО / А.О. Зінченко // Збірник наукових прачь Військового інституту телекомунікаиії та інформатизації Державного університету телекомунікацій” - 2014. - № 1. - С. 72 - 77.

6. Слюсар В. И. Семейство ториевых произведений матрии и его свойства / В. И. Слюсар // Кибернетика и системный анализ. - 1999.- Том 35; № 3.- С. 379 - 384.;

7. Слюсар В. И. Обобщенные ториевые произведения матриц в моделях циирровых антенных решеток $c$ неидентичными каналами / В. И. Слюсар // Известия вузов. Сер. Радиоэлектроника.- 2003. - Том 46, № 10. C. 9 - 17;

8. Слюсар B.I. Метод просторово-часового кодування сигналів тропосферного зв'язку на основі удосконаленої технології мульти-МІМО / В. І. Слюсар, М. О. Масесов // Збірник наукових прачь ВІТІ НТУУ “КПІ”. - 2009. - Вип. 1. - C. $132-136$.

9. Слюсар В. I. Технологія МУЛЬТИ-МІМО як засіб апаратного поєднання систем зв'язку та радіолокаиії / B. I. Слюсар, А. О. Зінченко // V-a науково-технічна конференція "Пріоритетні напрямки розвитку телекомунікаиійних систем та мереж спеціального призначення" (20 - 21 жовтня 2010 р., доповіді та тези доповідей). - Київ: ВІТІ НТУУ "КПІ", 2010. - С. 226 - 227;

Рецензент: д.т.н., проф., Заслужений діяч науки i техніки України Пермяков О.Ю., Національний університет оборони України імені Івана Черняховського, Київ.

\section{МАТРИЧНАЯ ФОРМАЛИЗАЦИЯ ОТКЛИКА МНОГОПОЗИЦИОННОЙ ИНТЕГРИРОВАННОЙ СИСТЕМЫ СВЯЗИ И РАДИОЛОКАЦИИ В РЕЖИМЕ СВЯЗИ}

\section{А. А. Зинченко}

В статье представлен вариант модели функционирования интегрированной многопозиционной системы связи и радиолокации по принципу МИМО в случае использования в приемных позициях плоских цифровых антенных решеток. Предложенная модель формализует отклик принимающего сегмента системы при условии излучения одним или несколькими передатчиками корреспондентов многочастотных сигналов на разных длинах электромагнитных волн.

Ключевые слова: мобильная станция связи, интегрированная многопозиционная система связи и радиолокации, изировая антенная решетка, матричная модель отклика. 
MATRIX FORMALIZATION OF RESPONSE MULTIPOSITION

INTEGRATED COMMUNICATION AND RADAR SYSTEMS IN THE COMMUNICATION MODE

\author{
A. Zinchenko
}

The paper presents a variant of the model functioning integrated multiway communication and radar systems on the principle MIMO in the case of positions in foster digital flat antenna arrays. The proposed model formalizes the response of the host segment of the system provided by one or more radiation transmitters correspondents multifrequency signals at different wavelengths of electromagnetic waves.

Key words: mobile communication station, integrated multy-position system communication and radar, digital antenna array response matrix model.

УДК 62-83::621.313.392

О.О. Кузнєцов

Академія сухопутних військ імені гетьмана Петра Сагайдачного, Львів

\title{
ПЕРСПЕКТИВИ ВИКОРИСТАННЯ ПРЯМОГО ПРИВОДА ПРИ МОДЕРНІЗАЦІЇ МЕХАНІЗМУ НАВЕДЕННЯ АНТЕНИ СТАНЦІЇ НАЗЕМНОЇ АРТИЛЕРІЙСЬКОЇ РОЗВІДКИ
}

Запропоновано при модернізації системи керування антеною станції наземної артилерійської розвідки використовувати ідеологію прямого привода. Проаналізовано особливості такого підходу, зокрема, використання моментних двигунів для прямого привода та вимоги до них.

Ключові слова: електропривод керування антеною, система наведення, безредукторний електропривод, моментна електрична машина.

\section{Вступ}

Постановка проблеми. Радіолокаційні станції (РЛС) призначені для розвідки наземних (надводних) рухомих цілей та обслуговування стрільби артилерії. На озброєнні артилерійських розвідувальних частин Сухопутних військ Збройних Сил України перебувають розвідувальні станції СНАР-10, АРК-1М, ПСНР-5к, та "Зоопарк-2", що у перспективі надійдуть на озброєння. Однак наявна техніка $€$ фізично та морально застарілою і не дозволяє повною мірою виконувати завдання артилерійської розвідки. Тому актуальною є задача пошуку шляхів модернізації розвідувальних станцій на основі нових досягнень науки і техніки.

Відповідно до стандартів НАТО, РЛС наземної розвідки можна класифікувати наступним чином [1]:

ближньої дії, що використовуються в розвідувальних, дозорних і патрульних підрозділах, а також у взводах;

малої дальності - у ротах (зона ведення розвідки $8 \times 5$ км);

середньої дальності $(15 \times 10$ км); середньої і великої дальності - в бригадах $(75 \times 30$ км $)$.

РЛС середньої і великої дальності в артилерійських розвідувальних частинах Сухопутних військ використовуються на комплексах СНАР-10 та АРК-1М. При їх модернізації необхідно в тому числі вирішувати питання приводу керування антеною.

Аналіз останніх досліджень і публікацій в напрямі побудови систем наведення показує, що у сучасних розробках широко застосовуються підходи, що передбачають відмову від проміжних ланок між силовими електромеханічними пристроями (двигунами) та об'єктами керування - ці системи отримали назву безредукторний або "прямий" привод. Так, у [2] вказаний підхід використано для електроприводів (ЕП) обертання антен судових РЛС, у [3] - для привода оптичного телескопа.

Мета роботи - $€$ розглянути перспективи використання систем ідеології привода, яка широко застосовується для побудови систем наведення, при модернізації систем керування антеною станції наземної артилерійської розвідки. 